\title{
The Contribution of Industry to Ship Design Education
}

\author{
J. Mikkelsen and S. M. Calisal \\ Department of Mechanical Engineering \\ University of British Columbia \\ mikk@mech.ubc.ca
}

\begin{abstract}
This paper details the Naval Architecture program at the University of British Columbia with emphasis on the delivery of the capstone design program in ship design. Since the enrollment is a small number of highly motivated students, the program instructors can utilize innovative project based learning strategies into the program. The paper highlights the iterative nature of ship design that is traditionally represented by a design spiral. In order to reinforce relevance and ensure that practices parallel those of industry, the instructors of the computer aided ship design course rely on the local Naval Architecture design firms to provide assistance to the students. This assistance is in the form of mentorship, access to proprietary design data and software, and student evaluation. In addition, the course instructors require that the student design teams complete a ship design that meets the requirements of an industry sponsored design competition. The paper illustrates the ship design process with an example of a student ship design project entered into an international competition.
\end{abstract}

\section{Introduction}

Over the past few centuries, the development of ships has significantly altered the course of humankind. Empires have been established, remote corners of the earth have been explored and settled, and major commerce between nations can all be attributed in one form or another to the development of ships. Recently, ship design has evolved into the design of advanced marine vehicles such as hydrofoils, multi-hulls, and surface effects ships. In addition, the last few decades have seen the development of offshore structures for energy exploration and extraction as well as aquaculture. When looking at the future, it is expected that humans' reliance on the oceans for food, transportation, energy, and recreation will only increase.

Today, the design of ships and offshore structures requires numerous engineering disciplines including hydrodynamics, structural engineering, mechanical engineering, power engineering, materials engineering, electrical engineering, and ergonomics, to name a few. In essence, a ship must contain all the elements of a small city but with the ability to travel on the harsh ocean environment.

Formal engineering training for the marine industry involves three primary disciplines: Naval Architecture, Marine Engineering, and Ocean Engineering. Although the disciplines are interrelated, there are distinct differences in responsibilities. From the definition provided by the Society of Naval Architects and Marine Engineers (SNAME), the governing technical marine society in North America; "Naval Architects are involved with basic ship design, starting with hull forms and overall arrangements, power requirements, structure, and stability. Some naval architects work in shipyards, supervising ship construction, conversion, and maintenance. Marine Engineers are responsible for selecting ships' machinery, which may include diesel engines, steam turbines, gas turbines, or nuclear reactors, and for the design of mechanical, electrical, fluid, and control systems throughout the vessel. Some marine engineers serve aboard ships to operate and maintain these systems. Finally, Ocean Engineers study the ocean environment to determine its effects on ships and other marine vehicles and structures. Ocean engineers may design and operate stationary ocean platforms, or manned or remote-operated sub-surface vehicles used for deep sea exploration"1.

In North America, there are more than twenty SNAME accredited universities and institutes that educate students in one or more of 
the three disciplines. Two of the institutes are in Canada, Memorial University of Newfoundland, and the University of British Columbia (UBC).

At the University of British Columbia, naval architecture has been taught as a technical elective within the Mechanical Engineering Department. This contrasts with most of the other accredited programs that have a dedicated degree program in Naval Architecture. The UBC program is relatively small with enrolment normally between six and fifteen students. The students that enrol in the courses are, in general, highly motivated and very interested in the subject. Students have had the opportunity to graduate with a degree in Mechanical Engineering with a minor in Naval Architecture. Recently, students have had little difficulty in obtaining employment in the industry and many have gone on become successful Naval Architects in design offices both locally and internationally.

\section{An overview of Ship Design Processes}

Before the "modern ship era," ships were normally designed using the well known basis ship approach. This approach involved developing a new vessel on an existing successful design. The new design would often be a reproduction of an existing so-called successful design, just by scaling it up or down with minimal alterations. Often, this type of design methodology led to vessels that were often unstable and inefficient. A good example is the Wasa, a Swedish flagship galleon that capsized in the Stockholm harbour minutes after her launch. This magnificent vessel, now housed in a museum, is a fine example of exquisite craftsmanship but it illustrates that a lack of knowledge in basic ship stability principles was held at that time.

The modern ship era began in the mid1800 's with the development of two significant events. William Froude's scientific approach to vessel performance prediction and the replacing of sail power with steam powered propulsion. Froude convinced the Royal Navy to build a towing tank in Torquay, England where he proved that model testing could be used to predict full-scale performance of vessels (proven to the British Admiralty with the famous HMS Greyhound tests). Following this key event, the application of scientific principles became the basis for much of the design of vessels.
As highlighted in the industry standard text by Taggert ${ }^{2}$, ship design usually consists of four major design steps starting with conceptual design, and leading through preliminary design, contract design and detail design. The conceptual design involves a technical feasibility study and the creation of different vessel alternatives. At this stage, some of the main ship characteristic such as length, beam, and power of the candidates are approximated.

In the preliminary design phase, these and other ship characteristics are further refined. Some of the vessel parameters such as length and beam are not expected to change following the completion of the preliminary design phase.

At the contract design stage, the design is further refined. Details such as completing the faired hullform, estimating the power requirements based on model tests and completing the general arrangement are some of the activities associated with this phase.

After the acceptance of the contract design, the detailed design for the construction of the vessel is prepared. Detailed work plans including construction details, installation plans, instructions to welders, etc. are all prepared in order to be passed to the production teams.

Different concepts in scientific ship design processes have been proposed, developed and modified, but the design spiral concept has been the most extensively used process up until the development of the fast computer computational system and optimization techniques. In 1959, Evans ${ }^{3}$ first visualized and modeled the process of ship design, now known as the "Ship Design Spiral" (Figure 1).

The spiral representation depicts the iterative nature of the process. The process begins with the mission requirement and proceeds through the nodes of the spiral towards the detail design. The four primary ship design steps are embroiled within the design spiral, although the concept is normally better suited to describe the latter stages of the design. The principle elements of this approach are goal directed, iterative, and a "sequential application of analyses based on the Newtonian principles of reductionism, mechanism and synthesis utilizing the intuitive skills of the designer." 3 Since each node can be complex and interdependent, it is often laborious and expensive. There have been several refinements made to the design spiral over time, but the basic features have remained unchanged. Buxton ${ }^{4}$ introduced economic issues into the spiral and time was added as a third dimension by Andrew $^{5}$ to create an iterative 
helical "corkscrew" (Figure 2). Andrew stated that the advantage of his representation is that constraints related to the design process and constraints originating from the design environment can be introduced.

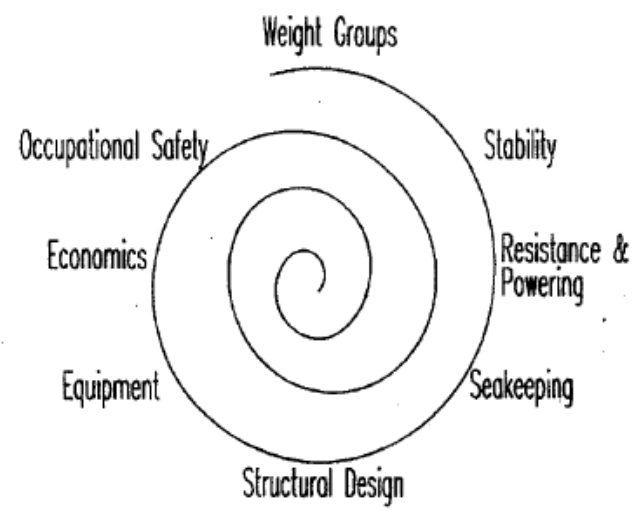

Figure 1. Ship design spiral.
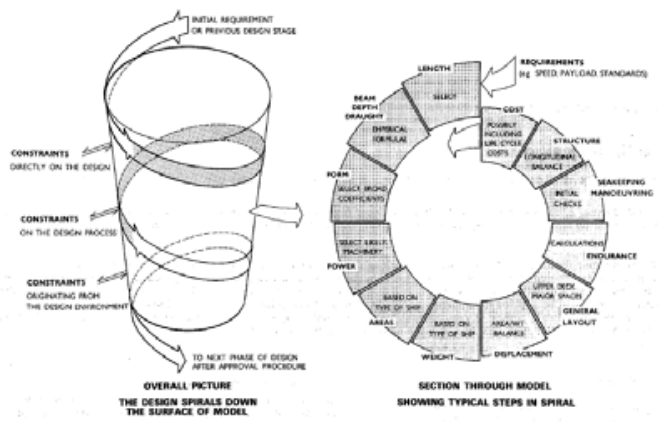

Figure 2. Andrew's overall model of the Ship Design Process ${ }^{5}$

Mistree et. a1. ${ }^{6}$ states that there are two salient features of the design spiral. Firstly, while spirals represent converging towards a product, the process is divergent with respect to information and the increasing detail of definition. Secondly, it is recognized that when the spiral was first formalized, it represented a descriptive model that portrayed how design was done. It represented both the state-of-art and the state-of-industry at the time.

Limitations of the design spiral are that the process of design relies on sequential activity and iteration. This traditional approach is slow and no longer competitive in the open market. Using this concept directly with the computer means that the computer is used as a high speed calculator rather than as an integral design tool. Though the spiral approach may result in a satisfactory design it does not promote the identification of superior solutions.
Mistree et. a1. ${ }^{6}$ criticized the design spiral approach as a process where it is difficult to incorporate concurrent (or simultaneous) engineering design. They proposed the so-called decision-based design in 1990. "Decision-based design encompasses systems thinking and embodies the concept of concurrent engineering design for the life cycle of the ship." This design process, according to this representation, takes place inside a funnel, or the frustum, in contrast to the spiral (Figure 3). Each aspect of the design, such as stability, is depicted as a generator line on the funnel. The design spiral runs as a helix on the surface. "The interplay between the numerous design considerations can be modeled effectively with information flowing through a ring of interaction" node. An irregular disk-like shape inside the funnel represents the degree of completeness of each node. In this representation, converging to a solution means the irregular shaped disc becomes circular.
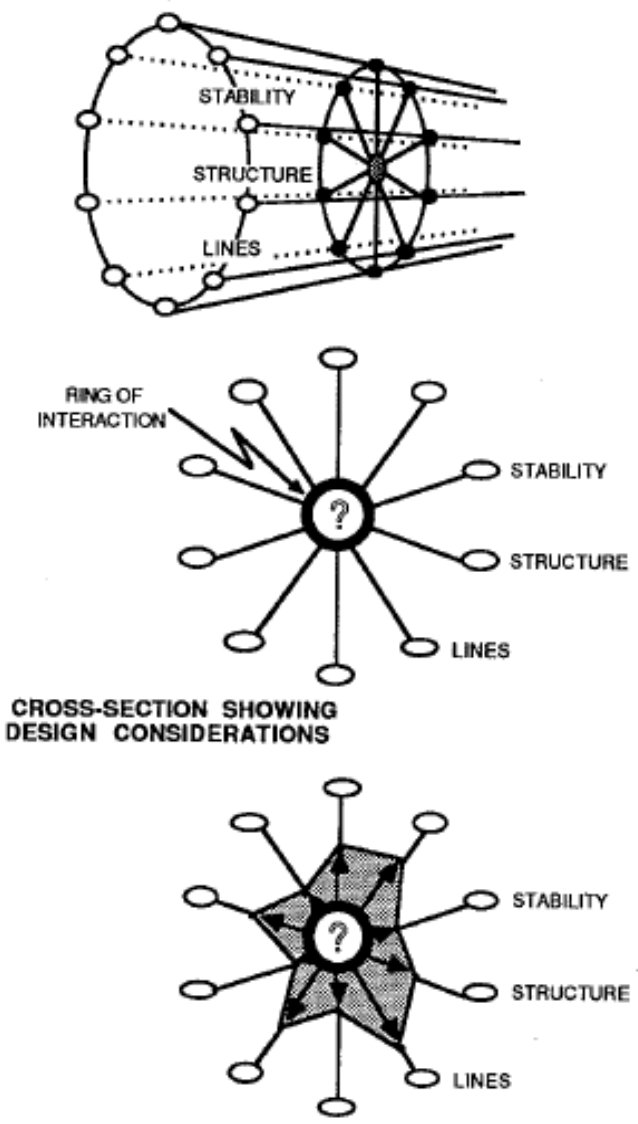

CROSS-SECTION SHOWING INFORMATION COMPLETENESS

Figure 3. Representation of design process by Mistree et al. ${ }^{6}$ 
Mistree et. $\mathrm{al}^{6}$. described different developments in ship design process. They highlighted two different model types for the design process in classical engineering design, namely, perspective models and descriptive models. The models are used to improve the efficiency and effectiveness of designers and the process they use. The perspective model of design consists of the following basic activities:

Analysis: A process of partitioning or decomposing any system into its subsystems and components to determine their individual and collective nature, proportion, functions, relationships, etc.

Synthesis: A process of integrating a collection of sub-systems, so as to create a system with emergent properties.

Evaluation: A process of assessing the degree to which a solution satisfies the goals that were originally stated.

According to the opinion of De Boer ${ }^{7}$, the basic three-step pattern of diverging, systemizing, and converging is generally recognized in each phase and sub-phase of a perspective model. In the first step of divergence, the designer generates a large number of ideas, alternatives and possible solutions. These ideas are then analyzed and synthesized in the second step, into forms that may represent acceptable solutions to the problem. And finally, the refined ideas are further synthesized, analyzed and evaluated to achieve the most acceptable solution. The model lends itself to the "design cone" of Mistree et. al.

As found in a more traditional product design model, the descriptive model of design consists of the following four basic activities:

Problem Analysis: A problem statement is developed.

Conceptual design: The statement of the problem is used to generate a collection of broad solutions.

Embodiment design: The solutions in the collection are refined for the purpose of eliminating the less satisfactory ones, until the final most satisfactory one remains.

Detail design: All the details of the final design are specified and the final design and documentation are produced.

The descriptive model follows the traditional ship design program while the perspective model is used to represent the specializations in ship design that is becoming more prevalent in modern design of ships.

Up until now, ship design was often limited to the designer's skill, experience, and the limited data available within the designers reach. Today, in the modern ship design process, developers are using concepts such as expert systems and knowledge bases to rapidly move through the design process. These forms of artificial intelligence are powerful tools to the Naval Architect and will continue to become more prevalent in the future.

\section{An Overview of the UBC Naval Architecture Program}

The Naval Architecture program at UBC consists of a total of five elective courses taken in the third and fourth years of the program. The two courses in the third year are introductory engineering science courses. The first course, ME340 - Statics of Marine Vehicles, covers topics such as ship stability, trim calculations, and preliminary structural analysis. The follow-up course, ME341 - Dynamics of Marine Vehicles, introduces the students to ship resistance estimation, propeller selection/design, and ship motions in a seaway (seakeeping). Both courses are delivered in a traditional lecture format with students completing mandatory readings and assignments. In addition, longer term assignments are assigned to pairs of students which normally require the application of ship analysis software. The most recent term project involved the design of a bulbous bow for a car ferry. This project involved the application of a mathematical potential flow solver, Michlet, to predict the wave resistance reduction of a typical local can ferry.

Following completion of the introductory courses, students can enroll into three specialized courses taken in the fourth year. The first course, ME443 - Experimental Naval Architecture, provides hands on experience in ship model testing. The course requires the use of the tow tank facilities at the nearby VizonSciTek Ocean Engineering Centre. The other two courses, ME442- Ship Structures, and ME441 Computer Aided Ship Design are taught as a form of project based learning (PBL). Project based learning replaces traditional lecture based courses with a focus on team projects designed to inspire self-learning in the required topics, team skills, and project management skills. In the area of Naval Architecture, several European schools have developed models of PBL including Delft University in Holland and Chalmers Institute in Sweden. At UBC, the low enrollment numbers in the senior naval courses 
allows the instructor to deliver project based learning courses to highly motivated students.

The project based Ship Structures course is designed with a core set of readings in areas such as advanced material sciences, solid mechanics, and classification rules that govern structural design of ships. Term projects, such as a modern structural design for the Titanic, are developed with the help of the instructor and by attending regularly scheduled tutorial sessions.

The capstone design course for the UBC Naval Architecture program is the Computer Aided Ship Design Course. In this course students are expected to apply previous knowledge with modern computer tools to design a vessel to meet a specific customer requirement.

Innovation in the ship design process requires modern computer systems to assist in the generation of hull lines, stability analysis, propulsion prediction, structural design, etc. Normally, the goal of all ship design instructors is to have students progress rapidly and efficiently through as many cycles of the design spiral as possible, in order that the design might include as many design parameters and contain as much detail as possible. Unless very small vessels are selected, the actual construction of a vessel or representative model is not feasible.

In addition to access to good design tools, teaching modern ship design to undergraduate students requires the skills and expertise of numerous experts from a variety of sources. Over the past few years, UBC has worked to integrate the expertise of various practicing professionals into the ship design course. This integration has included: having local naval architects act as industrial mentors and guest lecturers, allowing students access to proprietary design data and software, and providing evaluation at student presentations. Students value the access to practising engineers and the industry has often used the opportunity to recruit students into their design offices.

\section{Industry Sponsored Naval Architecture Design Competitions}

In general, the marine industry is very supportive of engineering education. The industry sponsors numerous scholarships, regularly hires students for work terms, subsidizes students to attend technical functions, participates in design courses, and through the technical societies, sponsors several design competitions. Through the Society of Naval Architects and Marine Engineers, there are a total of five separate design competitions in areas such as the design of large ships, small craft and yachts, commercial vessels, and designs for offshore oil and gas applications. Competitions attract participation from the major Naval Architecture/Ocean Engineering schools throughout the world including USA, Norway, Great Britain, Brazil, and Canada.

The principal objectives of the competitions as developed by SNAME are:

- To stimulate interest in ship/offshore design as a career choice

- To increase the participating students' understanding of, and competence in ship/offshore design

- To encourage project management and teamwork

- To develop mentor relationships between students and industry professionals

- To provide feedback to faculty members teaching ship and/or offshore design to aid in identifying areas of instruction that may require strengthening.

Judging committees are made up of wellrespected senior naval architects and ocean engineers. Since the judgment is based solely on the material presented in the submitted design reports, the reports need to be well written and complete. Judging committees are primarily interested in seeing evidence "that the student teams have achieved a good understanding of the design process, as indicated by the students' approach to their design project, the validity and comprehensiveness of the work done, the critical design decisions made along the way and the rationale for those decisions including, in support of the most critical decisions, the tradeoff studies performed." $" 8$

In order to ensure students develop competencies in key areas of Naval Architecture and Offshore Engineering, the competitions usually require details in several areas such as hull design and general arrangement, stability, general strength and structural design, hydrodynamics of motion, propulsion, costing, fabrication, and risk assessment. These competency areas are essentially all the nodes on the design spiral. Design reports are expected to be well written, complete, and well organized.

Since most design submissions involve computer generated results, judging committees require computer output and "evidence of understanding of the workings of the computer program used, its theoretical basis, its structure, 
restrictions on its applicability, the degree to which the program has been validated and accepted by the greater design community." 8

An innovative aspect of these competitions is the volunteer industry mentors. The organizers have solicited numerous Naval Architects to provide knowledge and guidance to the student teams. The mentors are grouped according to their particular expertise and experiences. Students are encouraged to contact mentors to ask operational questions and draw on their practical design experiences to help student teams develop robust and practical designs. It has been found that these contacts soon develop into strong mentor relationships between the students and vessel/offshore professionals that help students enter the professional field.

\section{An Example of a UBC Student Entry into a Naval Architecture Design Competition}

In the past year, as part of the Computer Aided Ship Design course, UBC Naval Architecture students have entered two SNAME sponsored competitions: the International Student Offshore Design Competition (ISODC) and the International Student Workboat/Small Craft/Yacht Design Competition (ISWSCYDC). A recent example of the UBC entry into the ISWSCYDC competition is the design of a fast response dive vessel, titled the Rescue Diver Deployment Vessel (RDDV) ${ }^{9}$. This example will highlight the evolution through the design spiral by the student design team.

The first aspect of the design is establishing the owner requirements. In this case, a recent tragedy involving the capsizing of a west coast fishing vessel illustrated the need for a dedicated high speed vessel designed to carry specialized rescue dive teams trained to enter capsized vessels. The three member student team approached specialized dive teams employed by the Canadian Coast Guard, Canadian Navy, and RCMP to determine a detailed set of client needs. The vessel needed to:

- Have a range of 120 to 320 naut. miles with a max. speed of 40 knots with 20 knot sustained speed in a storm.

- Be a shallow draft vessel with length between 50 and 70 feet and sufficient deck space for providing critical victim stabilization after recovery.

- Be equipped with a rapidly deployable 12 to 16 foot rigid hull inflatable.
- Be able to support multiple divers as they conduct recovery operations and have facilities to fill scuba tanks and rinse dive gear.

- Provide sickbay area for a minimum of two victim stretchers and sufficient room to perform Cardiopulmonary Resuscitation, treat victims of Hypothermia, and have the necessary equipment for victim care while in transit to the hospital.

Following the operational requirements, the next step for the team was to review potential hull form designs. For this application, the team considered SWATH (Small Waterplane Area Twin Hull), catamaran, planing and displacement mono-hulls and hovercraft designs. The team also reviewed hull construction techniques including welded steel, welded aluminium, and fiberglass lay-ups. In the end, the team selected an aluminium catamaran configuration based on the vessel's ability to maintain a balance of high speed and low draft characteristics while providing excellent stability during diving operations. Catamarans typically have up to $40 \%$ more usable deck area compared to other designs and operate at higher power to weight ratio than mono-hulls.

Once the vessel type was selected, the team began the task of establishing the general arrangement for the vessel. This required establishing the need for the work deck to allow diving activities, stretcher maneuvering and to support a recovery lift integrated into the aft deck. The students needed to consider adequate area in the main cabin to house the hospital area with sufficient storage for medical equipment, galley space, and a water closet. Next an elevated wheelhouse was required in order to provide the helmsman with good visibility to monitor activities in the water at the stern of the vessel and the ability to maintain adequate lines of sight to the bow of the vessel for docking and maneuvering in close quarters.

Figure 4 highlights an early iteration of the general arrangement for the main deck and the final proposed general arrangement of the vessel. The two figures illustrate the iterative nature of the process as more considerations such as entry ways and the rigid hull inflatable enter the design process and fairing the hullform.

From the general arrangement stage, information on overall length and beam requirements were used to develop a detailed lines plan for the hullform (Figure 5). For this application, an industry specific software 
package called AutoShip was used for modeling the three dimensional hullform. The vessel form was finalized after numerous iterations of the powering calculations, setting the hull spacing for fitting items such as engines and tanks, and the structural requirements. Final details included developing the hard chine to aid vessel planing, and the varying freeboard along the length of the vessel to accommodate easy water entry and exit of divers at the stern of the vessel, and greater freeboard at the bow to aid in seakeeping and operation in rough seas.
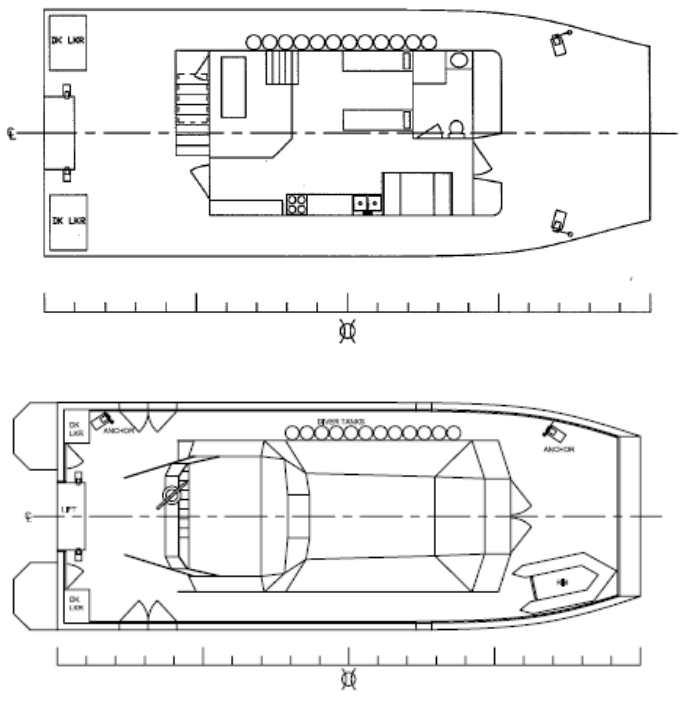

\section{Figure 4. Iterations of the general arrangement drawing}

A preliminary structural analysis was performed on the vessel to establish overall frame sizes, frame spacing, and plate thicknesses. Vessels of this type must be built in accordance to a classification society. A classification society (such as American Bureau of Shipping and Lloyds of London) provides approval for structural drawings and inspects vessels to ensure compliance with regulations (a similar role as building codes and city inspectors do for house construction). The hull structure was developed in accordance to American Bureau of Shipping (ABS) Guide for Building and Classing High Speed Naval Craft-2003. Using these rules, the team established the required moments of inertia for the hull and specified scantling sizes, plate thicknesses, material properties (AL5083 H116), etc. to exceed the minimum values dictated in the rules (Figure 6). Further analysis was performed to predict the strength of the deck connecting the two hulls of catamaran (called the wet deck). Stresses and deformations were evaluated in accordance to the ABS rules. The analysis utilized a Finite Element Analysis package (ANSYS) with the required loading and minimum stress levels established by ABS (Figure 7). For the design competition, all detailed calculations had to be included in an appendix for review by the judges. This is similar practice to industry where design calculations must be submitted to the governing classification society.

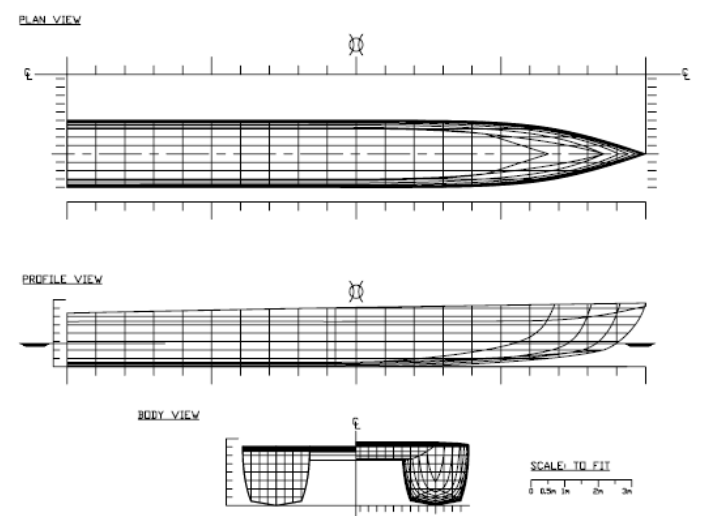

Figure 5. Final lines plan for catamaran

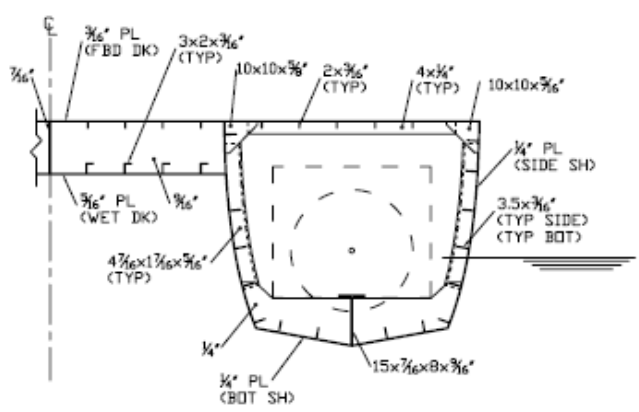

Figure 6. Structural detail of catamaran

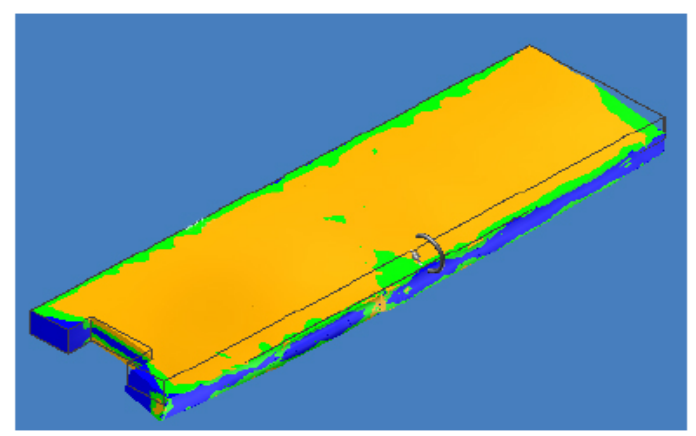

Figure 7. Stress analysis for wet-deck

The next steps on the design spiral involved estimating the weights and performing a stability analysis for the vessel. A commercial 
spreadsheet used by one of the local Naval Architecture design offices was used to develop the structural weight of the vessel on a frame-byframe basis. The weights of required machinery, tanks, etc. and their estimated locations were added to the program and finally a $10 \%$ margin was added to account for items neglected in the calculations. The required centers of gravity (longitudinal, vertical, and transverse) were then estimated. Once again, detailed calculations were submitted in the design report.

\section{Table 1. Summary of weight estimates for the catamaran vessel.}

$\begin{array}{lr}\text { Structure } & 11400 \mathrm{~kg} \\ \text { Machinery } & 7359 \mathrm{~kg} \\ \text { Tanks } & 4530 \mathrm{~kg} \\ \text { Electrical } & 949 \mathrm{~kg} \\ \text { Other } & 3200 \mathrm{~kg} \\ \text { Margin } & 1372 \mathrm{~kg} \\ \text { Total Weight } & 28809 \mathrm{~kg} \\ & \\ \text { CG Vertical } & 1.46 \mathrm{~m} \\ \text { CG Long. } & 7.26 \mathrm{~m} \\ \text { CG Trans } & 0.05 \mathrm{~m}\end{array}$

These weight calculations and centers of gravity were then used to predict the stability characteristic for the vessel. Several stability scenarios needed to analyzed in accordance to the regulatory agencies such as American Bureau of Shipping and Transport Canada. Stability scenarios included damage to the hull causing flooding in one or more of the watertight compartments, and studying the effects of severe storms (hurricane level) on the vessel. An example righting arm curve (stability performance in a hurricane force wind) is reproduced on Figure 8. Again detailed calculations were submitted to the judging committee for review.

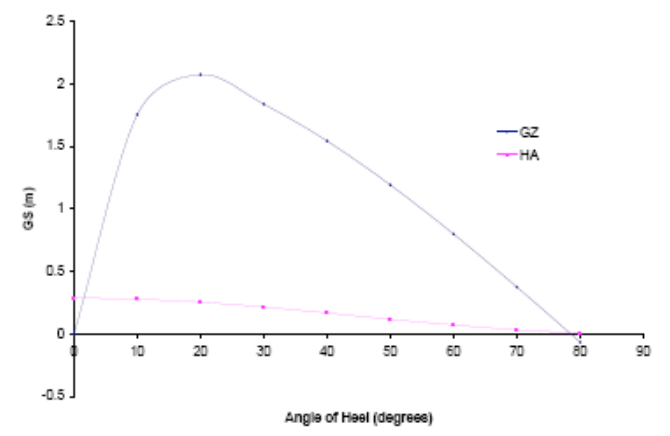

\section{Figure 10. Stability characteristics of} RDDV in severe storm condition

The resistance of the vessel was estimated using techniques learned in the resistance and powering course. These included numerical and analytical techniques to estimate the frictional resistance, wave making resistance and aerodynamic drag of the vessel (Figure 9). In addition, the students needed to find relevant powering and trim estimations from the general literature for planning catamaran vessels. The resistance values were then used for the selection of the appropriate propulsion system using the technical data supplied by the propulsion suppliers along with the engine suppliers.

Given the low draft requirements and safety concerns with divers in the water, waterjet propulsion was chosen over traditional propeller drives. Following reviews of manufacturing design charts and discussions with several waterjet and engine manufacturers, the team selected a pair of Lipps LJ43E waterjets manufactured by Wärtsilä-Lipps along with a pair of MAN Marine D2842LE404 Diesel engines (1282 HP rating). The MAN diesel engines were chosen due to the significant weight savings over other manufacturers such as Caterpillar and Detroit Diesel and their suitability for high speed applications. Figure 10 shows the overall machinery arrangement for the vessel.

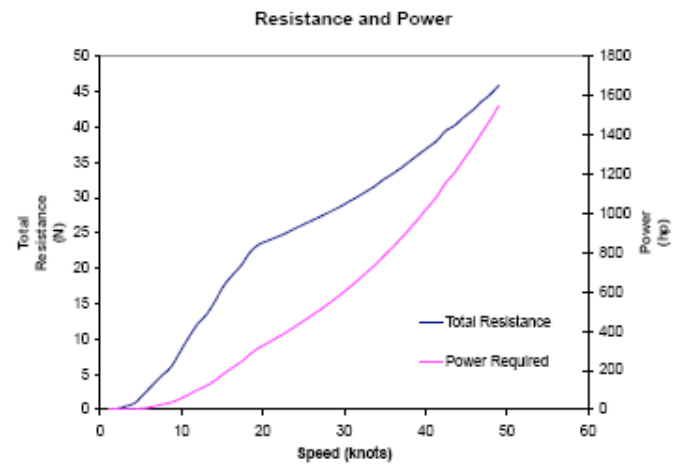

Figure 9. Resistance and power estimation curves

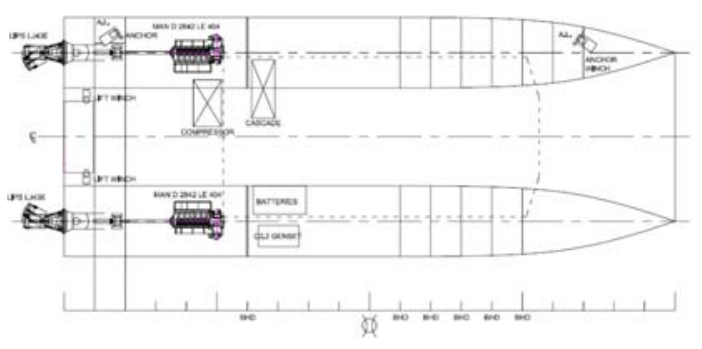

Figure 10. Machinery arrangement

Further steps in the design spiral included nesting the engines and waterjets into 
the hulls of the catamaran and adding the additional machinery requirements such as SCUBA tank compressor (Bauer Breathing Air System PK6 6000psi), electrical power generator set (Caterpillar C2.2 Genset), and anchor windlasses. Prior to selecting the generator and battery storage capacity, detailed electrical load estimations for all the systems within the vessel were performed. This load estimation included $\mathrm{AC}$ and DC (12 \& 24 volt) power requirements.

Next the fuel tank capacities were calculated based on the client needs for range, speed, and diving operations, and the predicted fuel consumption rates (Figure 11). The tanks were sized to fit within the hull frame spacing requirements developed from the structural analysis. Additional tanks for sea water ballast, fresh water supplies, grey water storage (sink wastes) and black water storage (toilet wastes) had to all be estimated and also sized to fit within the frames of the hull. A detailed tank plan and accompanying estimation calculations was included in the report for review.

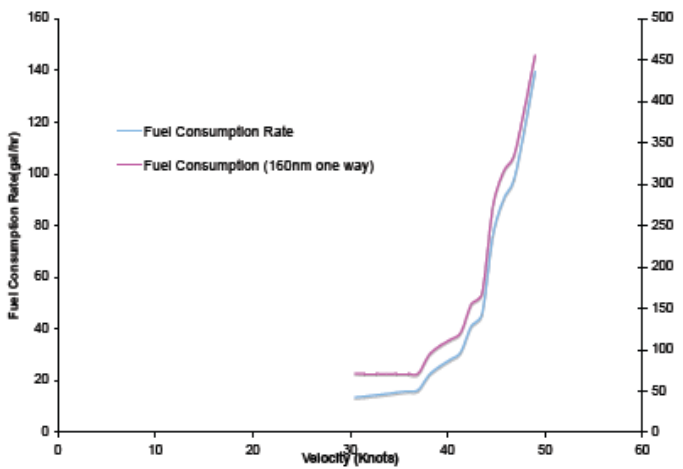

Figure 11. Fuel consumption vs. speed

The next step in the spiral was to review the sea worthiness of the vessel. Student members were required to obtain wave statistics for the expected operating regions for the vessel and apply motion analysis techniques learned in their previous courses. In this analysis, maximum motions for heave, roll and pitch were estimated based on the calculated dynamic response characteristics of the vessel and worst case scenario wave conditions, speed, and heading combinations. The analysis showed that the predicted motion values were within acceptable limits and demonstrated that the vessel would maintain approximately 20 knots speeds in most headings for over $99.9 \%$ of the conditions experienced in the Georgia Strait (the vessel's operating region).
The final step in this preliminary design was the cost estimation. Costs were estimated from manufacturer's quotations for specific equipment, and information provided by local Naval Architectural firms. It should be noted that without input from industry, accurate costing estimates for assembly labour (unit costs and welding time estimates) are very difficult to obtain. These values are normally proprietary information.

Table 2. Summary of estimated costs for the catamaran vessel rescue dive vessel.

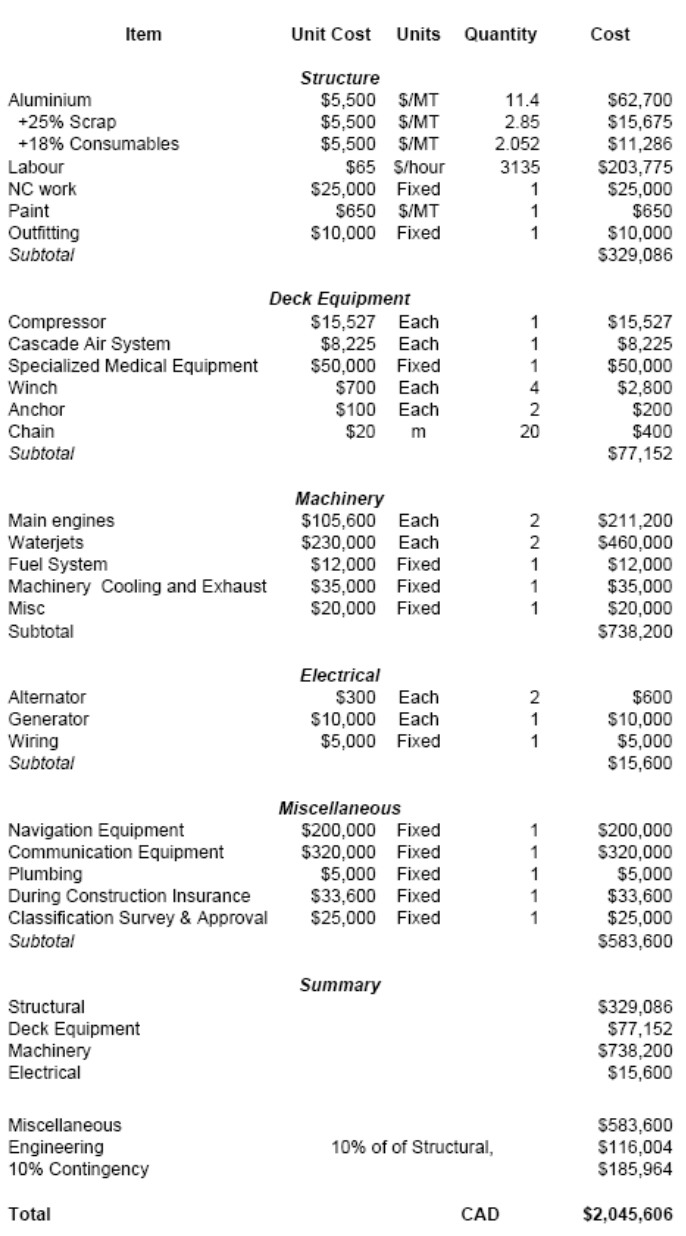

Having completed the first initial loops of the design spiral, the students completed a rendered drawing of the vessel (Figure 12) and completed a lengthy report (140 pages) for the design judges. The students presented their design to a panel of local naval architects and instructors for feedback and evaluation. At the time of the writing of this paper, the judging results of the design report have not been released. 


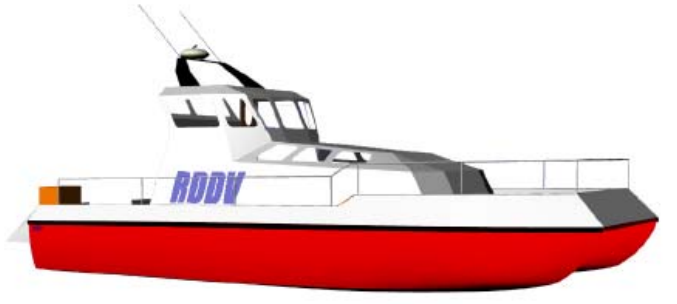

Figure 12. Rescue Diver Deployment Vessel

Studying the design loop process conducted by the students, one can conclude that students performed more of a perspective model of design rather than the linear descriptive model of design (according to Mistree et. al.). One can argue that each step in the loop required individual analysis, synthesis and evaluation. In earlier iterations of the design loop, changes to the design required a new analysis, and evaluation of earlier design steps. The tradeoffs and interdependency of each node supports the more complex versions of the ship design spiral. Without industry assistance, the student team would not have been able to achieve the quality and accuracy achieved in their design.

\section{Conclusions}

Teaching Naval Architecture design at UBC is a challenge given that the program is offered as an elective minor in a larger degree program rather than as a dedicated degree program. As illustrated by the design spiral concept, the ship design process is complex and iterative. The process can be best represented as a concurrent engineering design process where the decisions made at each node of the design spiral highly influence each of the other nodes. In order to successfully deliver a relevant capstone naval architecture program, one must enlist the help of the local Naval Architecture community. The industry, through the governing technical society, provides comprehensive design competitions that thoroughly challenge students in all areas of naval architecture. The industry provides invaluable mentorship/evaluation to the students, co-op work placements, and provides access to proprietary design data and software. Having the industry engaged in the education process strengthens the overall design experience for the students.

\section{Acknowledgements}

As discussed in the paper, a successful capstone Naval Architecture design course cannot be delivered without the support of the industry. From Robert Allan Limited, the authors thank Robert Allan, Grant Brandlmayr, Hans Muhlert, and Chris Mulder. From Aker Marine, special thanks to Dan McGreer, Mike Wadden, Milen Handjiyski, Mark Cooke and Dan Vyselaar (UBC/Aker Marine). The authors also thank Graham Shannon from Avia Design Group, Alan Reynolds from Offshore Research, Brian Konesky from BK Engineering, Brig Henry from AutoShip, and Ben Thompson from Lloyds Registrar. Special thanks to Gary Novelesky and Gerry Stensgaard from Vizon Sci-Tek Ocean Engineering Centre. Finally, the authors thank UBC students, Joel Atwater, Kolya Harpe, and Bill Rawlings for use of their design project.

\section{References}

1. Careers in the Maritime Industry, Society of Naval Architects and Marine Engineers, www.sname.org/careers May 22, 2005.

2. R. Taggert, Ship Design and Construction, Society of Naval Architects and Marine Engineers, $2^{\text {nd }}$ edition, May 1986.

3. J.H. Evans, Basic Design Concepts, Naval Engineers Journal, pp. 671-678, Nov. 1959.

4. I.L. Buxton, Engineering Economics Applied to Ship Design, Transactions of the Royal Institute of Naval Architects, Vol. 114, pp. 409-428, 1972.

5. D. Andrew, Creative Ship Design, Transactions of the Royal Institute of Naval Architects, Vol. 123, pp. 447-471, 1981.

6. F. Mistree, W. Smith, B. Bras, J. Allen, and D. Muster, Decision-based Design: A Contemporary Paradigm for Ship Design, SNAME Transactions, Vol. 98, 1990.

7. S.J. De Boer, Decision Methods and Techniques in Methodical Engineering Design, Academisch Boeken Centrum, DeLier, The Netherlands, 1989.

8. Dr. James Lisnyk Student Design Competition Official Rules Society of Naval Architects and Marine Engineers, www.sname.org/standing/education/Lisnyk/ rules.doc, May 31, 2005.

9. J. Atwater, K. Harpe, and B. Rawlings, Design of a Rescue Deployment Vessel, Final Report - MECH 441, University of British Columbia, June 2005. 